\title{
Production of Tea from Turkey Berry
}

\author{
Adonu Regina ${ }^{*}$, Amoah Millicent ${ }^{1}$, Mensah Eric ${ }^{2}$ \\ ${ }^{1}$ Faculty of Applied Sciences, Department of Hospitality Management, Takoradi Technical University, Takoradi, Ghana \\ ${ }^{2}$ Accra Technical University, Accra, Ghana \\ Email: ${ }^{*}$ regina.adonu@tpoly.edu.gh
}

How to cite this paper: Regina, A., Millicent, A. and Eric, M. (2018) Production of Tea from Turkey Berry. Open Access Library Journal, 5: e4316. https://doi.org/10.4236/oalib.1104316

Received: January 8, 2018

Accepted: July 13, 2018

Published: July 16, 2018

Copyright (C) 2018 by authors and Open Access Library Inc.

This work is licensed under the Creative Commons Attribution International License (CC BY 4.0).

http://creativecommons.org/licenses/by/4.0/ (c) (†) Open Access

\begin{abstract}
Tea is consumed for different reasons and by different people around the world. Most people are increasingly becoming aware of the benefits of consuming herbal beverages, hence the need for production of tea from health and medicinal plants. This work was aimed to produce tea from Turkey berry and access the acceptance of Turkey berry tea in when compared with other tea product on the market. Sensory evaluation was done on a five-point hedonic scale. The samples were: Sample A (100\% Lipton), Sample B (100\% Turkey berry tea), Sample C (Lipton with milk and sugar) and Sample D (Turkey berry tea with milk and sugar). The appearance, colour, taste and aroma of the Turkey berry tea were liked by the respondents. However, a few of them did not like the colour and aroma of the Turkey berry tea only (without milk).
\end{abstract}

\section{Subject Areas \\ Food Science \& Technology}

\section{Keywords}

Turkey Berry, Tea, Beverage, Herbal Tea, Sensory Evaluation

\section{Background}

Many people all over the world consume tea at different points in time for different purposes. According to [1], tea has been regarded for thousands of years in the East as a key to good health, happiness and wisdom. Fundamentally, tea should be pleasant to the senses. This means that, though it varies from one individual to the other, when one consumes tea, he or she should be able to experience some pleasurable attributes such as sweet fragrance, good taste and good feeling from his or her consumption and as such, teas that do not fulfil any of such experiences are often considered as having failed. 
Tea is produced from the leaves of a tea plant which is scientifically known as Camellia sinensis. However, there are different types of tea such as green tea, white tea, black tea, oolong and pu-erh tea as a result of the different processing methods used in production. Green tea, for instance, is produced from fresh tea leaves whilst some types of tea ingredients are intentionally broken during processing; others are steam dried in firing or baking [2].

Turkey berry is one of the vegetables that contain enormous health benefits and as such can be explored in the production of beverages. Being known among Indians as "Sunndakkai" and Ghanaians by several names such as "Amadweridi" or "Anona Ntroba" among the Fantes, "Nsusuwa" among the Kwahus and "Kantosi" among the Gas [3], Turkey berries (scientifically known as Solanumtorvum belonging to the plant family of Solanaceae) are believed to have originated from the southern part of the United States and can now be found in the tropical and subtropical countries of Asia, the Caribbean, South America and Africa. In Ghana, Turkey berries are normally found in the bushes or backyard gardens of many households. However, in Jamaica, India and Malaysia where it is revered for its high medicinal and food qualities with Indian having developed a lot of recipes for it, they are commonly found in markets [3].

The leaves and fruits of the Turkey berry plants are widely used as food and in traditional medicine around the world. In countries such as India and Ghana, the fruits are consumed directly or used to prepare soups and sauces as they contain a number of metabolites which have been shown to possess useful biological activities belonging mainly to steroid glycosides, flavonoid, vitamin B, vitamin C, iron, salts and steroidal alkaloids [4]. Also, Turkey berry extracts and metabolites, particularly those from leaves and fruits, are known to possess useful pharmacological activities. Literature on the benefits of the plant [4] [5] shows that Turkey berry leaves are mainly used for the treatment of fever, wounds, tooth decay, reproductive problems and arterial hypertension. Furthermore, some pharmacological studies have demonstrated that it has the ability to exhibit anti-oxidant, cardiovascular and nephron protective activities which support its traditional uses of killing germs, treating diarrhoea, stomach ache, piles, tuberculosis and also for curing cold and other chest and stomach related problems [3] [6].

Though Turkey berries have been with the people of Ghana since the beginning of the world, it was just in recent times that it has gradually gained popularity in the Ghanaian markets due to the awareness of people on its medicinal and health benefits by both orthodox and traditional care givers. In view of that many people have grown to realize the nutritional value of the plant especially for the preparation of soups and sauces. Turkey berries have now become a commonly sought after commodity [3]

The problem is that, though Turkey berries have gradually gained popularity in the Ghanaian markets and homes through their realization of the health benefits of the plant, their true values and variable uses are not fully known to consumers. As such many are just exposed to the traditional culinary uses of the 
fruits.

It is of this view that, this study seeks to use Turkey berry fruits to produce tea bags making it more convenient and also for consumers who are looking for healthy alternatives to the already existing beverages on the market.

\section{Materials and Methods}

\subsection{Materials}

Turkey berries used to be one of the most common vegetables on the Ghanaian market. They used to be found at almost every corner of the country, however, due to development more vegetation are being cleared to pave way for more construction works. Due to this, Turkey berries are not as common as they used to be and are even being sold commercially.

In spite of this, obtaining the raw materials for the production of the tea was not difficult as about $40 \%$ of the Turkey berries were obtained from the researcher's backyard garden (the Turkey berries were picked in the early hours of the morning between $6 \mathrm{am}-7 \mathrm{am}$ ), whiles the remaining was obtained from a local market (the Kotokuraba market at Cape Coast-the largest central market within the Central Region of Ghana). The sample of fully grown Turkey berries was selected for the production of the tea. All infected, ripped and damaged fruits were discarded. However, the best of the Turkey berries-those devoid of infection were selected since it has a significant effect on the final quality and taste of the tea.

\subsection{Method}

The preparation of the Turkey berry tea begun just after the needed fruits had been selected. The Turkey berry tea was produced from dried Turkey berry fruits, which involved harvesting of the fruits, washing, cutting, drying and milling after the Turkey berries were about 99\% dried using Solar energy. Figure 1 shows a flow chart of an adopted tea-making procedure from Eli Tea (2013).

\subsection{Statistical Analysis}

The statistical tools that were specifically applied in analysing the data were frequencies, percentages and averages using the version 17 of the SPSS Statistics computer software. The size of the number of respondents' responses affects the quality of the data which in turn tends to influence the results of the analyses from the study. In view of this, the result of the analysis on the respondents' response rate for the study is presented in Table 1.

\subsection{Sensory Analysis of Turkey Berry Tea}

Sensory analysis was carried out using a consumer preference test, specifically a ranking for preference at the Hospitality Management Department of Takoradi Technical University, TTU Takoradi, Ghana. According to [7], evaluation of foods can be either subjectively and objectively. Objective evaluation is 


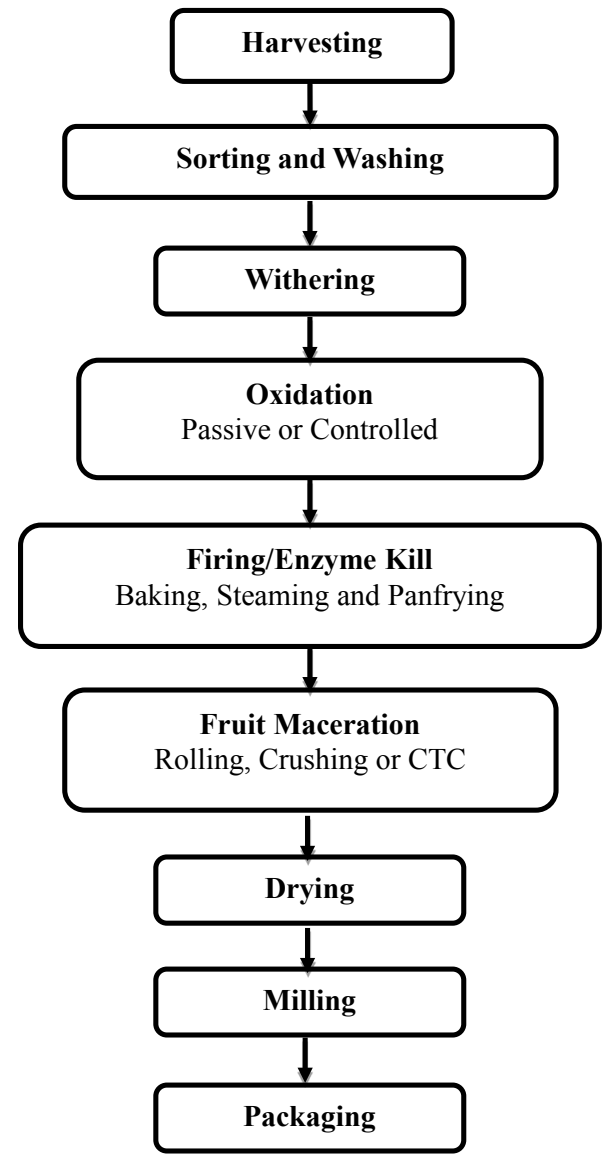

Figure 1. Flowchart for the production of Turkey berry tea.

Table 1. Response rate.

\begin{tabular}{cccccc}
\hline & \multicolumn{5}{c}{ Questionnaires } \\
\cline { 2 - 6 } & Distributed & \multicolumn{2}{c}{ Responded } & \multicolumn{2}{c}{ Not responded } \\
\hline Respondents & Frequency & Frequency & Percent & Frequency & Percent \\
\hline Lecturers & 16 & 16 & 26.7 & 0 & 0.0 \\
Students & 30 & 30 & 50.0 & 0 & 0.0 \\
Non-teaching staff & 14 & 14 & 23.3 & 0 & 0.0 \\
Total & 60 & 60 & 100.0 & 0 & 0.0 \\
\hline
\end{tabular}

Source: Field Work, June 2016.

conducted using machines to measure various physical aspects such as volume and tenderness of food, while subjective (or sensory) evaluation is done by people using their senses as instruments to evaluate such qualities of a food as appearance, aroma, flavour, and mouthfeel. The analyses were done by 60 untrained panelistswas selected from among the staff members and students of the Hospitality Management Department, Takoradi Technical University. The panelists was made up of 26 males and 34 females, with 25 of them between 18 - 25 years, 18 between 26 - 35 years, 11 between $36-45$ years and only 6 of them 
were either 46 years or above. For each sample, and for the same panellist, four repetitions were done. The panelists were asked to rinse their mouth with water after each tasting. Evaluation was done on a Five-point hedonic scale. The scale and categories were as follows: Excellent $=5$, very good $=4$, good $=3$, Satisfactory $=2$ and poor $=1$. The Characteristics evaluated included appearance, colour, aroma and taste. The samples were: Sample A (100\% Lipton), Sample B (100\% Turkey berry tea), Sample C (Lipton with milk and sugar) and Sample D (Turkey berry tea with milk and sugar). The panelists were not made known of the exact samples because codes were given to them.

\section{Results and Discussion}

\section{Assessment of Tea Samples' Aroma}

The sensory evaluation's result on the aroma of the samples of the tea that were made with Lipton as well as Turkey berry is presented in Figure 2. The respondents seem to like the aroma of all the tea samples. However, they indicated that they liked those with Turkey berry as the main ingredients (Turkey berry only tea, about $68 \%$ and Turkey berry tea with milk and sugar, about $88 \%$ ) better than those made with Lipton as ingredients (Lipton only tea, about $58 \%$ and Lipton tea with milk and sugar, about $72 \%$ ). It can be seen that the addition of milk and sugar improved the aroma of the tea with both ingredients and so none of the respondents disliked them by rating them as poor. On the other hand, a few of the respondents rated the Lipton only (about 3\%) and the Turkey berry only tea (about $3 \%$ ) as poor.

\section{Assessment of Tea Samples Colour}

The evaluation of the respondents regarding the colour of the tea made with different ingredients is presented by Figure 3.

With the exception of the Lipton with milk and sugar which had a few of the respondents (about 3\%) disliking its colour, none of the respondents reported of the other tea samples having poor colour. The Lipton tea with milk and sugar was also found to be the only tea sample with none of the respondents rating its colour as satisfactory. A maximum of about $67 \%$ of the respondents indicated that they liked the colour of the Lipton only tea (about 63\%) and Lipton tea with milk and sugar (about $67 \%$ ) whilst at least about $75 \%$ of them indicated that they liked the colour of the Turkey berry tea either with milk and sugar (about 78\%) or without milk and sugar (75\%).

Assessment of Tea Samples' Taste

Figure 4 presents the result of the analysis on the respondents' sensory evaluation of the samples of tea with regards to their taste. With about 58\%, 78\%, 62\% and $92 \%$ of the respondents rating the tastes of Lipton only tea, Turkey berry only tea, Lipton tea with sugar and milk, and Turkey berry tea with milk and sugar as very good, it can be observed that most of the respondents liked the taste of the teas very much. It can also be seen that the respondents liked the Turkey berry tea more than the Lipton one. However, the respondents were seen 


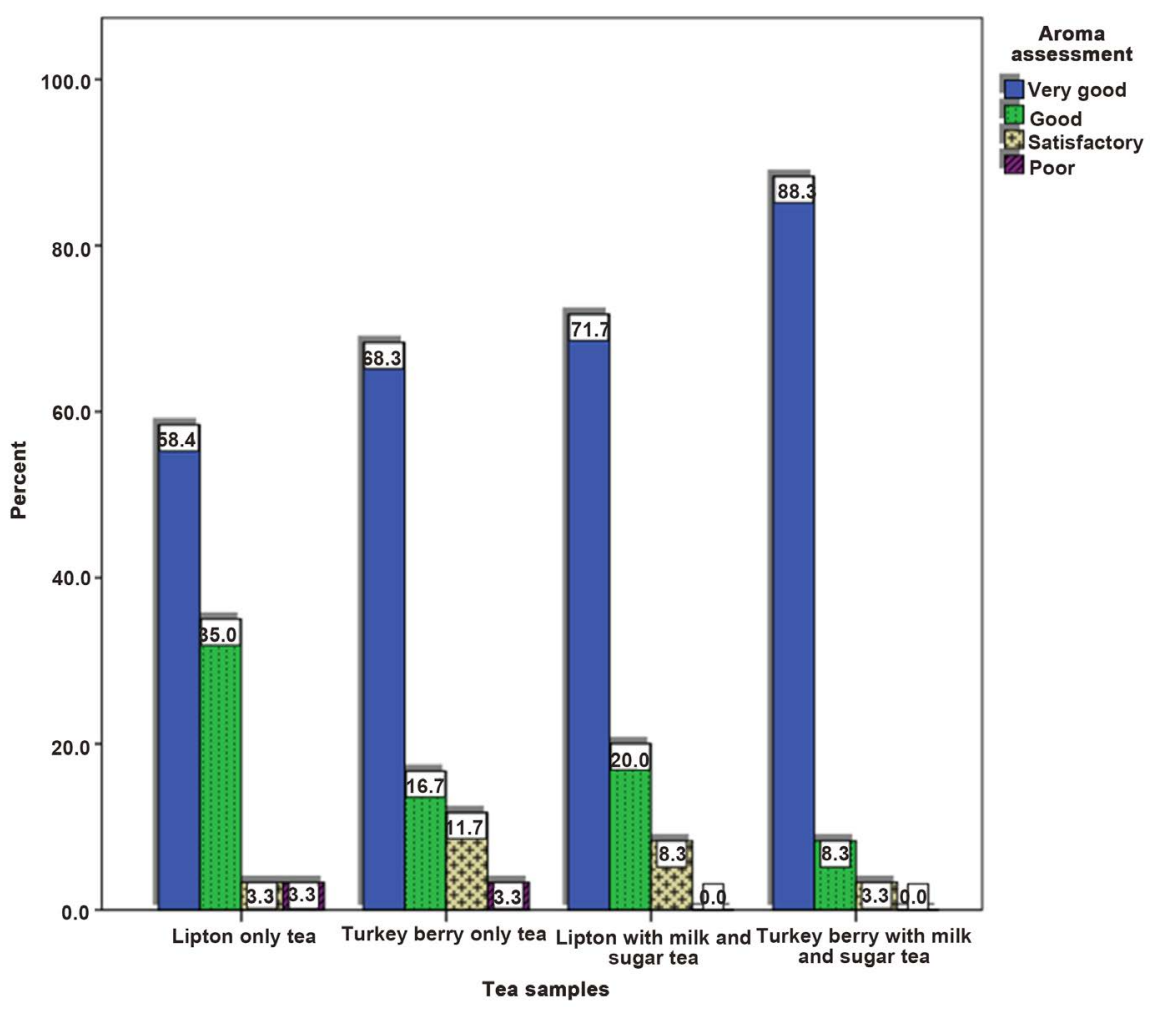

Figure 2. Respondents' assessment of the aroma of the tea samples. Source: Field work, June 2016 .

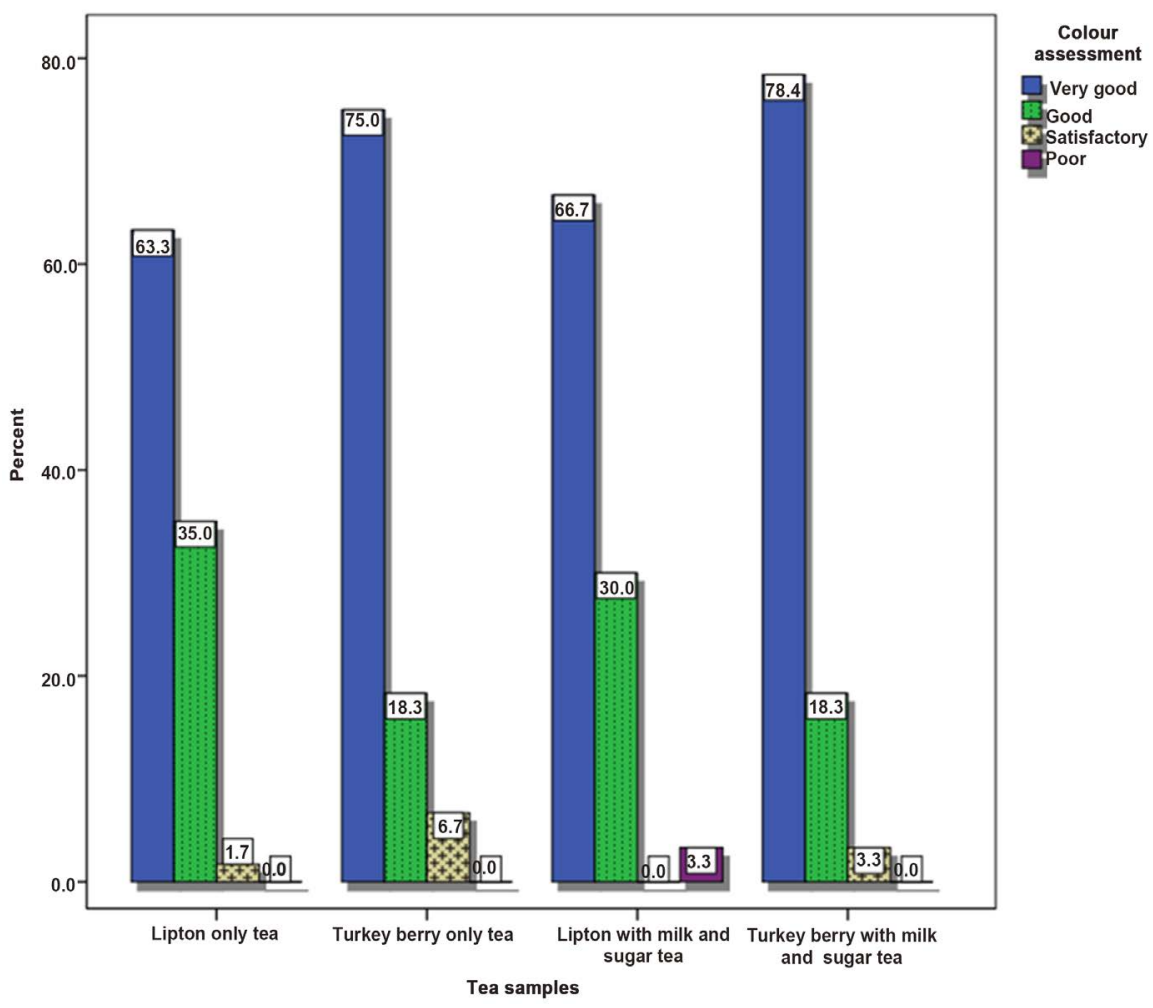

Figure 3. Respondents' assessment of the colour of the tea samples. Source: Field work, June 2016. 


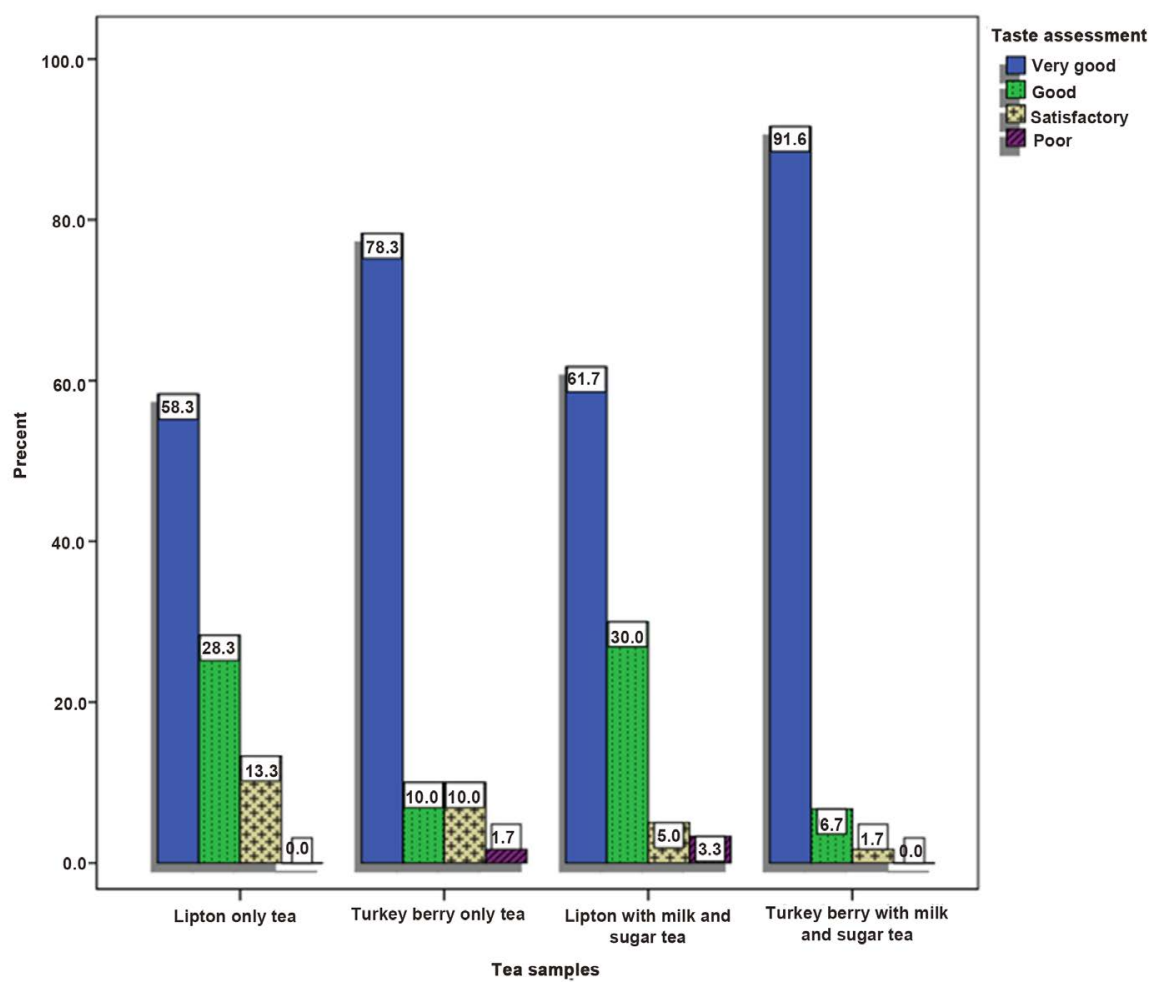

Figure 4. Respondents' assessment of the taste of the tea samples. Source: Field work, June 2016.

to have liked the Turkey berry tea with milk and sugar better. On the other hand, none of the respondents reported of disliking the taste of Lipton only tea and that of Turkey berry tea with milk and sugar though a few of them indicated that they did not like the taste of Turkey berry only tea (about 2\%) and that of Lipton tea with milk and sugar (about 3\%).

\section{Consumers' Acceptance of Turkey Berry Tea}

\section{Uniqueness of Turkey Berry Tea}

In assessing the general overview of the Turkey berry tea and how the Ghanaian market would receive it, the respondents were asked "How is the Turkey berry tea different from other brands of tea?" Their views were recorded, analysed and presented in Table 2. Close to half of the respondents (about 48\%) indicated that the Turkey berry tea is more nutritious than the other brands of tea. Also, a quarter of the respondents (25\%) reported that the Turkey berry tea does not taste bitter in relation to the others. A few of them, additionally, indicated that they the Turkey berry has an excellent colour (about $8 \%$ ) as well as a good aroma (about 7\%) than the others. This implies that the respondents liked the Turkey berry tea because it does not taste bitter and has a good taste, nutrients, good aroma and excellent colour than the others.

\section{Preference of Turkey Berry Tea}

It can be observed from Figure 5 that almost three-quarters of the respondents (about 73\%) indicated that they would prefer teas made of Turkey berries 
Table 2. Uniqueness of Turkey berry tea in relation to other brands of tea.

\begin{tabular}{ccc}
\hline Characteristics & Frequency & Percentage \\
\hline Taste good than others brand of tea & 7 & 11.7 \\
It is more nutritious than others brand of tea & 29 & 48.3 \\
Does not taste bitter & 15 & 25.0 \\
Has an excellent colour & 5 & 8.3 \\
Has good aroma than the others tea brand & 4 & 6.7 \\
Total & 60 & 100.0 \\
\hline
\end{tabular}

Source: Field work, June 2016.

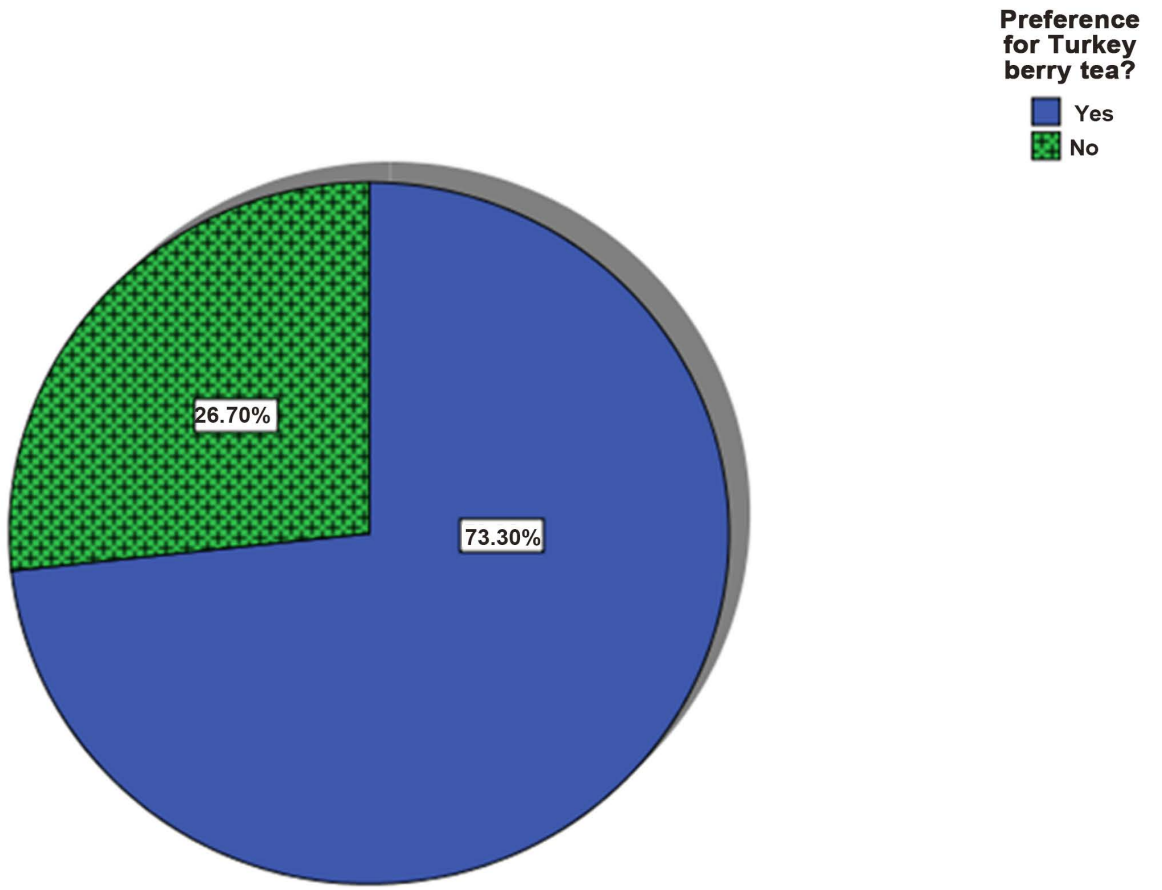

Figure 5. Respondents' preference of Turkey berry tea over the other brands of tea. Source: Field work, June 2016.

to those made from other ingredients. On the other hand, a little over a quarter of them (about 27\%) indicated that they would choose the other brands of tea to that made of Turkey berry. This implies that the respondents liked the Turkey berry tea and would patronize that over those brands made from other ingredients.

\section{Conclusion}

Based on the findings of the study, the study concludes that the Turkey berry fruits can be used to produce tea bags for consumption. This tea was found to be preferred over those made from other ingredientsby the respondents because itis nutritious, blood-replenishing, tasty and, generally, good for health issues.With regards to the sensory assessment of the tea samples, it can be concluded that the 
respondents generally liked the appearance, colour, taste and aroma of the Turkey berry tea. However, a few of them did not like the colour and aroma of the Turkey berry tea only (without milk). The Turkey berry tea was generally accepted by the respondents.

\section{References}

[1] Edgar, J. (2009) Types of Teas and Their Health Benefits. WebMD, LLC. http://www.webmd.com/

[2] Higdon, J.V. and Frei, B. (2003) Tea Catechins and Polyphenols: Health Effects, Metabolism, and Antioxidant Functions. Critical Reviews in Food Science and $\mathrm{Nu}$ trition, 43, 89-143. https://doi.org/10.1080/10408690390826464

[3] Asiedu-Addo, S. (2014) Turkey Berry: The Wonderful Medicinal Plant. Daily Graphic Online.

https://www.graphic.com.gh/features/features/turkey-berry-the-wonderful-medicin al-plant.html?fb_comment_id=600598819994672_879192362135315

[4] Herzog, F. and Gautier-Béguin, D. (2001) Uncultivated Plants for Human Nutrition in Côte d'Ivorie. http://www.fao.org/docrep/W3735e/w3735e10.htm

[5] Bown, D. (2014) The Royal Horticultural Society, Encyclopedia of Herbs. Dorling Kindersley Ltd.

[6] Haider, P. (2015) The Amazing Healing Qualities of Turkey Berries. https://www.linkedin.com/.../amazing-healing-qualities-turkey-berries-dr-paul-haid er

[7] McWilliams, M. (2013) Food Fundamentals. 10th Edition, Pearson Education, Inc., USA. 